\title{
QUANTIFYING SITE QUALITY IN A HETEROGENEOUS LANDSCAPE: RECRUITMENT OF A REEF FISH
}

\author{
Jeffrey S. Shima, ${ }^{1,3}$ Craig W. Osenberg, ${ }^{2}$ and Colette M. St. Mary ${ }^{2}$ \\ ${ }^{1}$ School of Biological Sciences, P.O. Box 600, Victoria University of Wellington, New Zealand \\ ${ }^{2}$ Department of Zoology, University of Florida, Gainesville, Florida 32611-8525 USA
}

\begin{abstract}
Heterogeneity in site quality can play an important role in patterns of abundance and population dynamics. Yet, estimating site quality in natural systems can be problematic because site quality can (1) vary through ontogeny for a focal organism, leading to shifts in site quality with age, (2) be confounded with (or masked by) variation in traits of individuals populating the sites, and (3) be correlated with local density. For example, if highquality sites attract more individuals but vital rates are density dependent, then observed vital rates will be relatively homogeneous in space despite strong heterogeneity in site quality. Here, we operationally define site quality for a reef fish as the mean survival time of juveniles transplanted to sites at a common density and size structure, with random assignment of individuals to sites to remove potential confounding effects of local variation in individual quality and density. Our assays using juvenile age classes of the six-bar wrasse (Thalassoma hardwicke) showed that site quality varied in space (i.e., among patch reefs) but was constant through time. Site quality increased with availability of the branching coral Pocillopora (which is used as a refuge), but decreased with density of a predator, the arc-eye hawkfish, Paracirrhites arcatus (which also uses Pocillopora). We experimentally added colonies of Pocillopora to reefs and (1) increased site quality, (2) enhanced natural settlement rates of sixbar wrasse, but (3) attracted more hawkfish predators, and (4) did not increase survival of juvenile fish under ambient densities. Our results suggest that Pocillopora increases site quality, but attracts greater densities of settlers and predators, resulting in increased density dependence and predation, which mask the underlying effects of Pocillopora on site quality (supporting the hypothesis of "cryptic density dependence"). Variation in site quality and the possible confounding effects of density and individual traits warrant more experimental study.

Key words: cryptic density dependence; environmental variability; habitat quality; post-settlement mortality; predator-mediated effect; predator-prey interaction; site quality; spatial refuge.
\end{abstract}

\section{INTRODUCTION}

Many species exhibit patchy distributions, with habitat patches (e.g., patch reefs surrounded by sand or meadows surrounded by forest) occupied by individuals which interact over relatively small spatial scales in comparison to the dispersal potential of their offspring (Hanski 2002, Palumbi 2004). The quality of the habitat patches can vary in time or space, as may the quality and/or density of the organisms using these patches (Pettorelli et al. 2001, Pfister and Stevens 2003, Shima and Osenberg 2003, Helms and Hunter 2005, Donahue 2006). Here, we refer to the combined effects of local abiotic processes (e.g., nutrient loading or soil traits) and interspecific interactions (e.g., competition and predation), but not conspecific interactions, on a focal species as "site quality." This definition is similar to "habitat quality" of Muller et al. (1997), but it more explicitly emphasizes the local nature of the effect. Spatial and

Manuscript received 8 January 2007; revised 8 May 2007; accepted 21 May 2007. Corresponding Editor: J. F. Bruno.

${ }^{3}$ E-mail: Jeffrey.Shima@vuw.ac.nz temporal variation in site quality is a common feature of many ecological systems (Carr 1994, Ostfeld et al. 1997, Franklin et al. 2000) and can influence a variety of demographic rates (e.g., growth [Steele and Forrester 2002, Srinivasan 2003], survival [Caley et al. 2001], and migration [Jonsen et al. 2001, Cronin 2003]). The overall performance (e.g., fitness, per capita survival, population growth rate, individual size or condition) of individuals at a particular site will depend on the local site quality, the intrinsic quality of individuals (e.g., due to traits such as size and condition of individuals that populate a site), and local conspecific density. Importantly, site quality, individual quality, and local density can covary with one another (e.g., Pettorelli et al. 2001) such that the effects of site quality may be masked by density-dependent effects (Shima and Osenberg 2003) or heterogeneity in individual quality (Shima et al. 2006; see also Donahue 2006, Stamps 2006). Thus, the pattern of covariance among these factors will greatly affect our assessment of site quality and its heterogeneity in space and time.

Understanding the drivers and consequences of site quality for a given system has important implications for 
metapopulation dynamics, conservation, resource management, and restoration (e.g., Franklin et al. 2000, Battin 2004, Schumaker et al. 2004, Donahue 2006). Yet, assessing site quality for many systems remains problematic. For example, (1) environmental features related to site quality may not be immediately apparent to scientists (Wilson and Osenberg 2002, Stachowicz and Byrnes 2006); (2) multiple factors that drive heterogeneity in site quality may not be independent of one another (Phillips 2005); (3) different demographic rates may respond differently to environmental factors and may give different rankings of site quality; and (4) measurement of site quality must be made independently of variation in the density of conspecifics (e.g., if high quality sites contain more individuals and density dependence occurs, then these sites may not appear to be better than lower quality sites [e.g., Shima and Osenberg 2003]). Consequently, understanding the causes and effects of variation in site quality may require a more sophisticated approach than simply quantifying observed variation in vital rates (Van Horne 1983, Battin 2004). The challenge then is to describe performance in relation to all three variables (site quality, individual quality, and local density), or at least, remove the effects of two variables while quantifying the effects of the third.

Here, we take a phenomenological approach to the problem of assessing site quality. Using juvenile stages of a coral reef fish as a model system, we control for variation in individual quality and density and compare survival across a wide range of environments to quantify heterogeneity in site quality. We define a set of environmental features that appear to be correlated with site quality and then manipulate those features in a controlled field experiment to assess their effects on multiple demographic rates and other putative sources of site quality. Our work explicitly examines patterns of covariance between components of quality and how this covariance structure can confound observational assessments of site quality. In particular, our previous observations led to a hypothesis (which we term "cryptic density dependence") which predicted that high-quality reefs (due either to variation in site or individual quality) receive more settlers, but because survival is density dependent, quality masks the deleterious effects of density (Shima and Osenberg 2003). Our current study was designed to test components of this hypothesis and evaluate whether site quality alone (vs. individual quality) could account for the observed patterns of cryptic density dependence.

\section{Methods}

\section{Study system}

All field work was conducted on small patch reefs within the shallow lagoons surrounding the island of Moorea, French Polynesia $\left(17^{\circ} 30^{\prime} \mathrm{S}, 149^{\circ} 50^{\prime} \mathrm{W}\right)$. Reefs selected for this study were isolated from one another by expanses of sand or coral pavement, ranged in size from
5.5 to $28.6 \mathrm{~m}^{2}$, and were heterogeneous in substrate composition to maximize variation in site quality (e.g., reefs were composed of variable proportions of live coral [predominately Porites lobata and/or P. rus, often surmounted by smaller colonies of fine branching corals, e.g., Pocillopora sp.] dead coral patches, and/or algae [e.g., turfs associated with the territorial damselfish Stegastes nigricans or macroalgae such as Turbinaria sp.]).

We quantified habitat attributes by visually estimating percent cover of substrate categories (e.g., coral/macroalgae species, dead coral substrate, turf, and so forth; our visual estimates are highly concordant with fixed-point contact methods for quantifying cover; J. S. Shima and C W. Osenberg, unpublished data; see also Dethier et al. 1993). The surface area of each site, and of all fine-branching coral colonies (e.g., Pocillopora spp., Acropora spp.) within each site, were estimated from an ellipsoid formula, using measurements of maximum length, maximum perpendicular width, and height. We recorded the depth of each site as the distance from the water surface to the base of each patch reef. We estimated an index of isolation for each site as the proportion of a 2-m "halo" around each reef that was occupied by adjacent upright reef (as opposed to sand or pavement).

\section{Estimating variation in site quality}

We explored variation in site quality and its effects on demographic rates of the six-bar wrasse, Thalassoma hardwicke. Like many reef fishes, six-bar wrasse produce offspring that complete a period of larval development in an offshore pelagic environment before settling back to reefs. Consequently, young six-bar wrasse that settle to patch reefs can vary in their individual quality (e.g., size, age, or energy stores) as a result of variation in their larval and/or parental history (Shima et al. 2006; see also McCormick and Molony 1995, McCormick 2006). The number of larval six-bar wrasse that settle to a site is variable in space and time (Shima 1999, 2001a). Thus, there is likely considerable spatial variation in local density, site quality, and individual quality. Therefore, quantification of site quality must be accomplished after removing possible effects of local density and individual quality.

Assays of site quality.-To estimate variation in site quality independent of individual quality and density, we conducted a pair of assays that followed survivorship of standardized additions of young six-bar wrasse across sites that differed in their substrate composition. For each assay, we collected recently settled fish (using clove oil and hand nets; all fish were $<24 \mathrm{~mm}$ standard length [SL]) from reefs outside of our study area and randomly assigned individuals to groups of a fixed number and similar size structure. Immediately prior to transplantation of cohorts back to focal reefs, reefs were cleared of all six-bar wrasse $<30 \mathrm{~mm}$ SL to facilitate identification of our untagged fish and eliminate effects of intraspecific competition from similar sized conspecifics. All other 
fish were left undisturbed (i.e., other resident fish may contribute to site quality). Using this approach, we assume that random assignment of individuals to our constructed groups, followed by random assignment of groups to focal reefs, removes any prior covariance between individual quality and site quality.

For the first assay, nine six-bar wrasse were added to each of 16 reefs and daily surveys of six-bar wrasse abundance and size structure over the next six days were used to estimate mean survival times (based upon timing of losses of individuals of known size). On the final day of the first assay, reefs were cleared of surviving six-bar wrasse and a second assay was then initiated on the same day. For the second assay, 10 six-bar wrasse were transplanted to the same 16 reefs. Unlike the first assay, initial losses of six-bar wrasse were replaced with similarly-sized individuals at $\sim 12 \mathrm{~h}$ and $\sim 24 \mathrm{~h}$ after initial transplantation, to compensate for losses potentially attributable to handling effects. By $\sim 24 \mathrm{~h}$ following initial transplantation, all reefs had 10 focal six-bar wrasse. Surveys to estimate survival times of focal individuals were initiated $\sim 36 \mathrm{~h}$ after initial transplantation for the second assay, and these continued at a daily frequency for $10 \mathrm{~d}$, and at a 2-d frequency for an additional week. For both assays, abundance and identity of potential competitors (e.g., other labrids and scarids) and potential predators were also recorded (after Shima and Osenberg 2003). Concurrent monitoring of similar nonfocal reefs within each of our two spatial blocks (i.e., where six-bar wrasse $<30 \mathrm{~mm}$ total length [TL] were removed but no new fish added) suggested that natural settlement was minimal or absent during the time period of our assays (i.e., estimates of survival times of focal assay fish were unlikely to have been confounded by natural settlement). We implemented two different approaches to stocking reefs (i.e., with and without replacement) to generate complimentary information (i.e., to test for an interaction between handling artifacts and site quality) and to ensure that estimates of site quality were robust to variation in methods.

Survival analysis.-We used survival analysis (PROC LIFEREG, SAS v. 9.1) with a Weibull distribution to explore patterns of variation in survival times of transplanted six-bar wrasse among reefs and between assays (our full model included an interaction term for reef and assay). Additionally, the LIFEREG procedure of SAS generated parameter estimates for each reef $x$ assay combination, and we converted the parameter estimates to "mean survival times" for each reef in each assay by taking the product of the exponentiated intercept parameter, $I$, and the factorial of the SAS "scale parameter," $s$ (i.e., mean survival time $=s ! e^{(I)}$ ). We interpreted "mean survival time" in these assays as direct estimates of site quality for juvenile six-bar wrasse because assays were conducted at a common density using a random sample of individuals (hence avoiding confounded effects of local density and individual quality). We evaluated consistency of variation in site quality (i.e., between the two assays), by examining the main effect of reef in the statistical model and by calculating the correlation between mean survival times (log-transformed to improve normality) for each reef during the two surveys (extracted from the parameter estimates from the full model).

\section{Environmental correlates with site quality}

Our assays estimated site quality among 16 reefs that varied in habitat attributes (e.g., reef size, isolation, depth, substrate composition, refuge availability) and fish assemblages (e.g., potential competitors, predators). We used exploratory analyses (using PROC GLM, SAS v. 9.1) to identify potential environmental correlates with our estimates of site quality. Our exploratory models incorporated all combinations of (1) spatial block effects, (2) habitat attributes (as single variables and as PCA-derived composite variables), and (3) fish assemblage attributes (time-averaged across period of each assay and included as single variables, functional group aggregates, and as PCA-derived composite variables). These analyses suggested that the two most important variables were (1) time-averaged densities of the arc-eye hawkfish, Paracirrhites arcatus (a confirmed predator of young six-bar wrasse, J. S. Shima and C. W. Osenberg, unpublished data) and (2) area of the finebranching coral Pocillopora sp. (a probable refuge from predation). Consequently, we focused on these two parameters and used a general linear model to examine the effects of hawkfish density, Pocillopora area, and their interaction on site quality.

\section{Experimental manipulation of site quality}

Because our exploratory analyses suggested that Pocillopora cover was an important determinant of site quality, we designed a field experiment to test (and estimate) the effects of Pocillopora on (1) natural settlement of young six-bar wrasse, (2) survival of naturally settling six-bar wrasse (i.e., the combined effects of site quality, individual quality, and density dependence), (3) mean survival time of fish transplanted at a common density (to isolate the effect of site quality from wrasse density and individual quality), and (4) abundance of arc-eye hawkfish (a predator that also uses Pocillopora and may influence its effects).

We used 64 isolated patch reefs (i.e., sites) distributed evenly among four spatial blocks. Within each spatial block, sites were randomly assigned to one of two treatments ("Pocillopora addition" or a "control"). Overall, 32 reefs (eight per block) received five transplanted Pocillopora heads, while 32 control reefs (eight per block) received similar disturbance from divers without the addition of Pocillopora. We collected colonies of Pocillopora sp. (each colony measuring $\sim 15 \mathrm{~cm}$ diameter) from the shallow fore-reef slope (where Pocillopora is naturally abundant) and transplanted them to our "Pocillopora addition" reefs using Z-Spar Splash Zone epoxy (Carboline, St. Louis, 
Missouri, USA) during December 2004. Pocillopora colonies responded well to transplantation, with $>90 \%$ of transplanted colonies surviving in good condition (i.e., with $>75 \%$ of individual colony alive and unbleached) for the duration of the experiment.

\section{Patterns of natural settlement, predator attraction and juvenile accumulation}

Visual censuses of all sites, at $\sim 4-5 \mathrm{~d}$ intervals from January to June 2005, were done to quantify patterns of six-bar wrasse settlement, densities of surviving six-bar wrasse juveniles (i.e., recruits) and densities of arc-eye hawkfish. New settlers were visually identified on the basis of size and color pattern (see Shima 1999, $2001 a, b$ ). Densities of surviving juveniles for each site were estimated as the time-averaged counts of individuals measuring 15-30 mm SL, standardized by reef surface area. Hawkfish densities were estimated as the time-averaged counts standardized by reef area. Densities were averaged over the last four censuses for two of our spatial blocks (where wrasses were cleared on the last two censuses as part of our site quality assay) and for the last six censuses for the remaining two blocks.

Effects of Pocillopora additions on natural settlement and juvenile six-bar wrasse density were evaluated separately using an ANCOVA that included effects of treatment (Pocillopora addition vs. control), spatial block (four regions), hawkfish density (the covariate), and all possible interaction terms. Effects of Pocillopora additions on hawkfish densities were similarly analyzed, but without the covariate. The full models were simplified by sequentially removing nonsignificant terms. Dependent variables comprised of density estimates (derived from count data) were square-root transformed to improve normality.

Assays of site quality.-In early June 2005, we cleared resident six-bar wrasse $<30 \mathrm{~mm}$ TL from all "Pocillopora addition" and "control" sites within two of our spatial blocks. We then transplanted standardized groups (i.e., collections of individuals randomly assigned to groups in a predetermined size structure) of six young six-bar wrasse (14-19 $\mathrm{mm} \mathrm{SL})$ to sites and monitored survivorship, as in the site quality assays described above. Survival analysis was used to generate sitespecific "mean survival times." Log-transformed mean survival times were evaluated initially in a full general linear model with main effects of treatment and spatial block, a covariate (hawkfish density, time-averaged over duration of the assay), and all possible interaction terms. Nonsignificant interaction terms were removed sequentially to construct a reduced model.

\section{Covariance between settlement and site quality: a test of cryptic density dependence}

The "cryptic density dependence" hypothesis (CDD [Wilson and Osenberg 2002, Shima and Osenberg 2003; see also Fretwell and Lucas 1970]) predicts that fish should colonize (settle to) sites in proportion to site quality and that this covariance in settlement intensity and site quality will obscure patterns of densitydependent mortality when assessed across sites. To evaluate this hypothesis, and evaluate if variation in site quality (vs. individual quality) was responsible for observed patterns of $\mathrm{CDD}$, we examined correlations between observed natural settlement (recorded in visual censuses conducted at $\sim 4-5 \mathrm{~d}$ intervals between January and April 2005) vs. a reef-specific estimate of site quality (i.e., log-transformed mean survival times) derived from (1) the natural gradient based on two quality assays using 16 reefs (two spatial blocks) and (2) the experimental gradient (Pocillopora addition) based on one quality assay using 32 reefs (four spatial blocks). We combined the two reef-specific estimates of site quality from the natural gradient using a principal components analysis (i.e., we used the first principal component score for each reef as the aggregate measure of site quality). We then used ANCOVA to evaluate variation in cumulative settlement as a function of (1) our estimate of site quality, (2) spatiotemporal block effects (six blocks, two from the natural gradient and four from the experimental gradient), and (3) the interaction term. CDD predicts a positive correlation between settlement and site quality, and our ANCOVA model evaluated this prediction for each set of sites in a single analysis.

We used ANCOVA to evaluate the correlation between the log-transformed mean survival time of naturally settling fish and site quality (estimated from assays using a fixed density of fish). CDD predicts no correlation between natural survival time and site quality because "quality" estimated from naturally settling fish is confounded by density-dependent mortality: i.e., if higher quality sites receive proportionately more settlers, then their overall survival will be the same as observed on low-quality reefs (but with few setters). Our ANCOVA model evaluated this prediction for each set of sites in a single analysis. Nonsignificant interaction terms were removed from analyses.

\section{RESUlts}

\section{Consistent variation in site quality}

Survival of transplanted young six-bar wrasse varied significantly among sites and between the two assays (survival analysis; site, Wald $\chi^{2}=49.27, P<0.0001$; assay, Wald $\chi^{2}=32.33, P<0.0001$; interaction, Wald $\chi^{2}$ $=15.23, P=0.43$ ). Survival times, overall, were elevated in the second assay. The absence of a significant interaction between "site" and "assay" and the presence of a significant "site" effect indicates that the pattern of variation in quality among reefs was consistent through time. This temporal concordance in site quality can be visualized as the positive correlation in site quality between the two assays (Fig. 1).

\section{Environmental correlates with site quality}

Our analyses suggest an important interaction between Pocillopora area and hawkfish density (interac- 


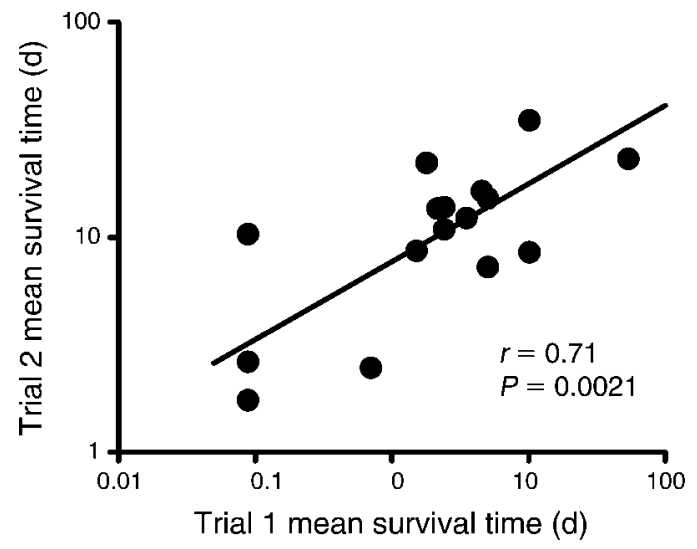

FIG. 1. Covariation in survival times of juvenile six-bar wrasse, Thalassoma hardwicke, randomly allocated and transplanted in standardized densities and size structures to a set of 16 sites at two different times ("Trial 1" and "Trial 2"). Concordance between these two assays shows temporal consistency in site quality (i.e., survival at a common density of fish). The fitted line is the principal axis $(y=0.886+0.363 x)$. Note the $\log$ scales on the axes.

tion, $F_{1,28}=12.01, P=0.0017$; main effect Pocillopora, $F_{1,28}=11.83, P=0.0018$; main effect of hawkfish, $F_{1,28}=$ $1.10, P=0.30$ ). For sites where hawkfish were rare or absent, increasing Pocillopora area greatly improved site quality (Fig. 2), but in sites with hawkfish, there was no demonstrable effect of Pocillipora, suggesting that the predator precluded the use of this habitat.

\section{Effects of Pocillopora additions on settlement, survival, predator density, and site quality}

Adding Pocillopora to reefs increased settlement of six-bar wrasse (Fig. 3A; controlling for significant variation among blocks, $F_{3,59}=9.11, P<0.0001$; main effect of treatment, $F_{1,59}=4.75, P=0.033$ ). Pocillopora additions also increased densities of hawkfish (Fig. 3B; controlling for significant variation among blocks, $F_{3,59}$ $=28.10, P<0.0001$; main effect of treatment, $F_{1,59}=$ 10.69, $P=0.018$ ) and juvenile six-bar wrasse (Fig. 3C; block effect $F_{3,59}=5.13, P=0.0032$; main effect $F_{1,59}=$ $5.13, P=0.027)$. The survival assay using a standard density, size structure, and quality of six-bar wrasse demonstrated that Pocillopora increased site quality (Fig. 3D; $F_{1,30}=12.66, P=0.0013$ ).

\section{Covariance between settlement and site quality:} a test of cryptic density dependence

Natural settlement was positively correlated with site quality (ANCOVA, $F_{1,42}=7.38, P=0.0095$; when controlling for blocks, $F_{3,42}=6.25, P=0.0012$; nonsignificant interaction term removed). In contrast, survival of naturally settling six-bar wrasse was not significantly correlated with site quality (ANCOVA, $F_{1,27}=0.19, P=0.66$, when controlling for blocks, $F_{3,27}$

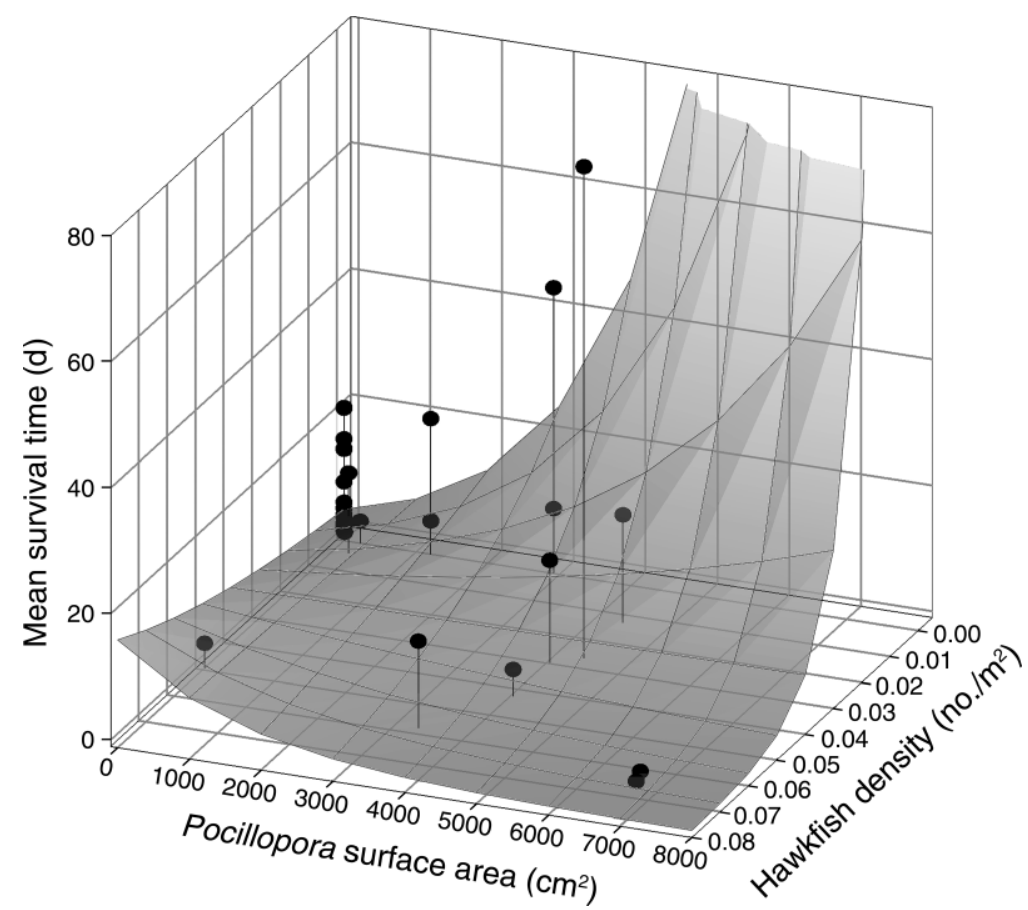

FIG. 2. Mean survival times of juvenile Thalassoma hardwicke in relation to (1) surface area of the branching coral Pocillopora sp. (a refuge) and (2) local density of hawkfish, Paracirrhites arcatus (a predator). In the absence of hawkfish, T. hardwicke survival increased with Pocillopora cover, but this effect was absent (or reduced) in the presence of hawkfish, suggesting that hawkfish preclude access of $T$. hardwicke to this microhabitat. Actual data are given (solid circles) along with the fitted response surface (generated from back-transformed GLM [general linear model] parameter estimates). 
$=1.21, P=0.32 ;$ nonsignificant interaction term removed). Thus, natural settlement compensated for variation in site quality, leading to no demonstrable relationship between survival and site quality when assessed using ambient (vs. fixed) settler density. These patterns are consistent with the predictions of cryptic density dependence (Wilson and Osenberg 2002, Shima and Osenberg 2003).

\section{Discussion}

Heterogeneity in site quality can affect a suite of ecological processes, such as population dynamics, life history evolution, and habitat selection (Van Horne 1983, Pulliam 1988, Donahue 2006, Stamps 2006). Heterogeneity in site quality is particularly critical in applied contexts, where source and sink habitats need to be clearly distinguished, for example, in the siting of reserves or selection of sites for habitat restoration (Lipcius et al. 1997, Crowder et al. 2000, Cabeza 2003). Though heterogeneity in site quality is a relatively straightforward concept, assessments of this variation can be surprisingly challenging. Rapid assessments often use estimates of abundance (or density) of a focal species as surrogates for site quality (e.g., "indicator species") despite well-known problems with this approach (reviewed in Van Horne 1983). Even more sophisticated assessments of site quality that incorporate animal preference patterns or more direct estimates of demographic rates can be problematic (e.g., Battin 2004) because animal preferences are not always optimized and because different demographic rates and age classes may vary in their responses to site quality. This issue is especially challenging when sites vary in density of a focal organism and density dependence affects organismal performance beyond the baseline effects of habitat per se. In these situations, density can mask (or exacerbate) underlying gradients of site quality, depending on the correlation between density and quality (Wilson and Osenberg 2002).

For T. hardwicke, the covariance between settlement intensity and site quality approximates an ideal free distribution (sensu Fretwell and Lucas 1970; see also Osenberg et al. 2006). Post-settlement survival of six-bar wrasse is density dependent (Shima 1999, 2001b, 2002), the strength of density dependence (site quality) varies among sites (Shima and Osenberg 2003), and settlement is greater to sites with weaker density dependence. As a result, density dependence is difficult to detect without an experimental manipulation. We call this phenomenon cryptic density dependence (Shima and Osenberg 2003), and it gives rise to relatively equal survival across sites that vary in settler density and site quality (Wilson and Osenberg 2002). Similar phenomena have been described more recently for other reef fishes (e.g., Holbrook and Schmitt 2003, Forrester and Steele 2004, Overholtzer-McLeod 2004, Schmitt and Holbrook 2007), salmonids (Achord et al. 2003), crabs (Donahue 2006), and aphids (Helms and Hunter 2005). Stamps (2006) proposed a conceptual model to account for
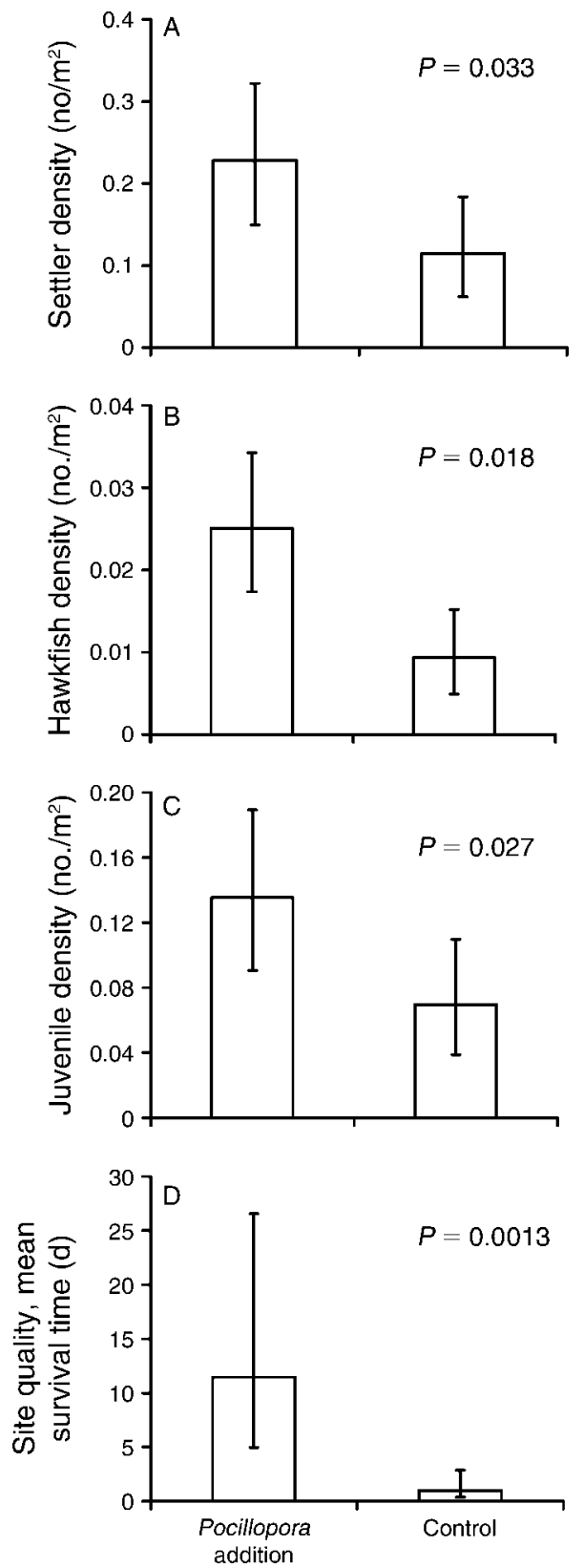

FIG. 3. Effects of experimental additions of Pocillopora on (A) density of new settlers of $T$. hardiwicke, (B) hawkfish densities, (C) density of juvenile T. hardwicke accumulated over a settlement season, and (D) site quality, as estimated by the mean survival time of juvenile $T$. hardwicke that were transplanted to reefs at a common abundance and size structure. Presentations in panels (A)-(C) give back-transformed, least-square means with $95 \% \mathrm{CI}$, following adjustment for block effects. Panel (D) gives survival time (mean with $95 \%$ CI) estimated from survival analysis; block effects were not significant in this analysis. In each panel, the $P$ value of the main effect of treatment is given.

covariance between individual quality and site quality and describes some implications of these patterns that underlie cryptic density dependence. We note that such patterns have long influenced studies of birds (e.g., 


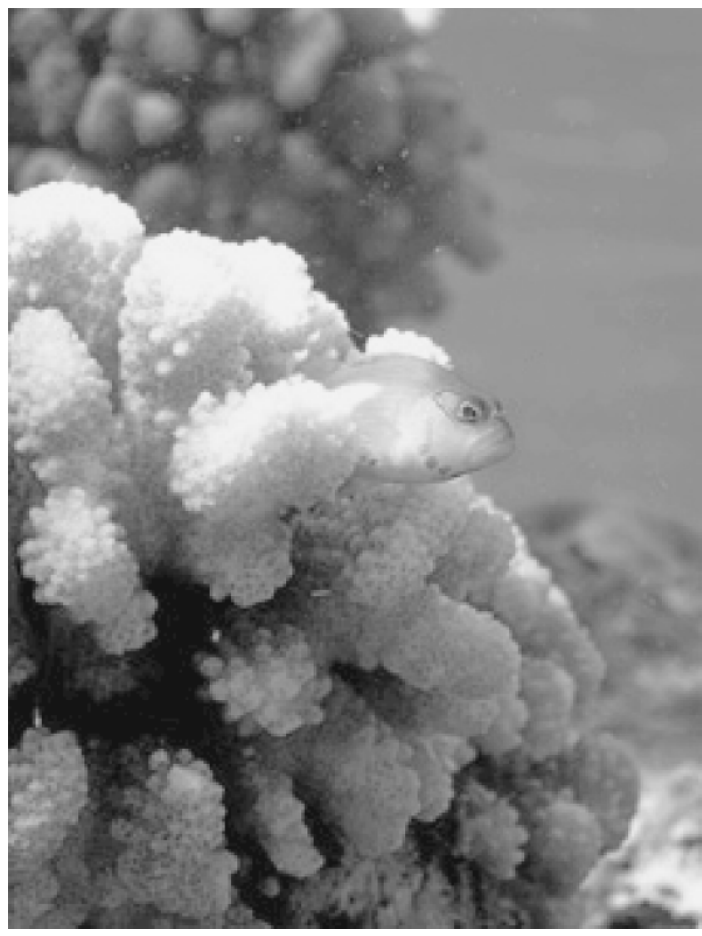

FIG. 4. Transplanted colony of branching coral Pocillopora sp. patrolled by the predatory hawkfish Paracirrhites arcatus. Photo credit: J. Shima.

Fretwell and Lucas 1970), although these observations have more typically been interpreted in the context of fitness-maximizing strategies (perhaps because more direct estimates of fitness are obtainable for nesting birds). Given the growing number of reports of related phenomena, we expect that cryptic density dependence is likely a common feature of many ecological systems.

A consequence of cryptic density dependence is that heterogeneity in site quality itself may be cryptic: covariance between the strength of density dependence and ambient densities will give the false appearance that all sites are roughly equivalent in their ability to support (in this case) fish populations, for example, if ambient survival is used to assess site quality. As a result, the only way to reveal the underlying differences among sites in quality is to compare performance (e.g., survival) of individuals at a common density: i.e., experimental assays are required to decouple the opposing effects of density and site quality.

In our system, two factors play primary roles in determining site quality for the six-bar wrasse: (1) the density of predatory hawkfish, which decreases site quality and (2) the availability of a refuge (the finebranching coral, Pocillopora), which increases site quality. What is particularly interesting about these two features is that they are correlated: hawkfish use the same habitat as its prey ( $T$. hardwicke), and thus a potential refuge for $T$. hardwicke also harbors a possible predator (Fig. 4). This joint use of a common habitat may be a general feature of many predator-prey systems (Murdoch 1994, Hixon and Carr 1997, Gotelli and Ellison 2006). Perhaps because of this joint use of a refuge habitat by predator and prey, hawkfish and Pocillopora have a complex interactive effect on site quality (Fig. 2). In the absence of Pocillopora, hawkfish have little, if any, effect on site quality (i.e., survival time): site quality is uniformly poor in the absence of a refuge. However, with relatively high cover of Pocillopora, hawkfish play an important role: in their absence, site quality is extremely high, but when present, hawkfish reduce quality to levels as poor as observed in the absence of Pocillopora.

These reef systems contain diverse suites of predators, of which hawkfish are only one. Thus, we suggest that this strong interaction between the effects of Pocillopora and hawkfish arises because hawkfish may increase the vulnerability of six-bar wrasse to other predators within the system (typically these are larger species that do not shelter within Pocillopora). A similar mechanism of riskenhancement has been described for other multiplepredator systems (e.g., Sih et al. 1998, Vonesh and Osenberg 2003). Hawkfish routinely perch atop colonies of Pocillopora and behave as ambush predators. Although they are capable of eating small fishes (we have observed attacks on T. hardwicke), it is possible that hawkfish themselves impose relatively little direct mortality on $T$. hardwicke (a conjecture supported by our casual observations). However, hawkfish may exacerbate the effects of other predators, especially in the presence of a microhabitat that could otherwise be used as a refuge from these predators but is instead occupied by hawkfish. Similar synergistic effects of ambush and mobile predators have been observed in other reef systems (e.g., Hixon and Carr 1997).

Experimental additions of Pocillopora not only increased site quality as assessed by post-settlement survival (at a fixed density), but they also increased settlement of six-bar wrasse. Although the mechanism is unclear, six-bar wrasse preferentially settled to sites of higher quality. Related work (Lecchini et al. 2007) suggests that young six-bar wrasse have the sensory capabilities to discriminate among habitat features and disproportionately choose Pocillopora over other substrates shortly after settlement. They also may be attracted to sites with more conspecifics. Of course, this higher settlement is, in part, what masks variation in site quality.

Because we randomly assigned fish to sites, our assays allowed us to isolate effects of "site quality" from heterogeneity in "individual quality" (i.e., where some sites are simply occupied by "better" individuals), two features that might be correlated in many systems (e.g., Pettorelli et al. 2001, Reitzel and Chockley 2005; reviewed in Stamps 2006). Thus, we know that habitat features extrinsic to the fish themselves (e.g., Pocillopora) play an important role in spatial variation in site quality. These results, however, do not preclude a role 
for spatial variation in individual quality under ambient conditions. Indeed, our previous work (Shima et al. 2006) suggests that sites with high cover of Pocillopora (i.e., high quality sites) also harbor fish with greater proportional energetic content and faster larval growth. It is likely that both "site quality" and "individual quality" contribute to recruitment success of six-bar wrasses on patch reefs within this system. Furthermore, these factors probably positively covary, leading to stronger spatial patterns than might otherwise be expected (Stamps 2006).

Overall, we suggest that "cryptic site quality" may be a common phenomenon of many ecological systems and that underlying variation in site quality can be revealed only by assays that remove the confounding effects of density and/or individual quality. These cryptic effects, and the absence of a more mechanistic understanding of site quality, can result in surprising and possibly adverse consequences for natural resource management, conservation, and ecological restoration. Using assays to assess quality from the point of view of the focal organism is a useful, and perhaps underused approach, particularly when no simple relationships between environmental features and site quality can be presumed.

\section{AcKnowledgments}

We gratefully acknowledge the field assistance of S. Geange and S. Miller. Versions of this manuscript benefited from constructive comments of the Shima-Phillips lab group and from two anonymous reviewers. This research was funded by NSF (OCE-0242312) and an ISAT Linkage Grant from the Royal Society of New Zealand. This is contribution number 160 from UC Berkeley's Richard B. Gump South Pacific Research Station, Moorea, French Polynesia.

\section{Literature Cited}

Achord, S., P. S. Levin, and R. W. Zabel. 2003. Densitydependent mortality in Pacific salmon: the ghost of impacts past? Ecology Letters 6:335-342.

Battin, J. 2004. When good animals love bad habitats: ecological traps and the conservation of animal populations. Conservation Biology 18:1482-1491.

Cabeza, M. 2003. Habitat loss and connectivity of reserve networks in probability approaches to reserve design. Ecology Letters 6:665-672.

Caley, M. J., K. A. Buckley, and G. P. Jones. 2001. Separating ecological effects of habitat fragmentation, degradation, and loss on coral commensals. Ecology 82:3435-3448.

Carr, M. H. 1994. Effects of macroalgal dynamics on recruitment of a temperate reef fish. Ecology 75:1320-1333.

Cronin, J. T. 2003. Matrix heterogeneity and host-parasitoid interactions in space. Ecology 84:1506-1516.

Crowder, L. B., S. J. Lyman, W. F. Figueira, and J. Priddy. 2000. Source-sink population dynamics and the problem of siting marine reserves. Bulletin of Marine Sciences 66:799820.

Dethier, M. N., E. S. Graham, S. Cohen, and L. M. Tear. 1993. Visual versus random-point percent cover estimations: "objective" is not always better. Marine Ecology Progress Series 96:93-100.

Donahue, M. J. 2006. Allee effects and conspecific cueing jointly lead to conspecific attraction. Oecologia 149:33-43.

Forrester, G. E., and M. A. Steele. 2004. Predators, prey refuges, and the spatial scaling of density-dependent prey mortality. Ecology 85:1332-1342.
Franklin, A. B., D. R. Anderson, R. J. Gutierrez, and K. P. Burnham. 2000. Climate, habitat quality, and fitness in Northern Spotted Owl populations in northwestern California. Ecological Monographs 70:539-590.

Fretwell, S. D., and H. K. Lucas. 1970. On territorial behavior and other factors influencing habitat distribution in birds. Acta Biotheoretica 19:17-36.

Gotelli, N. J., and A. M. Ellison. 2006. Food-web models predict species abundances in response to habitat change. PLOS Biology 4:1869-1873.

Hanski, I. 2002. Metapopulation ecology. Oxford University Press, New York, New York, USA.

Helms, S. E., and M. D. Hunter. 2005. Variation in plant quality and the population dynamics of herbivores: there is nothing average about aphids. Oecologia 145:197-204.

Hixon, M. A., and M. H. Carr. 1997. Synergistic predation, density dependence, and population regulation in marine fish. Science 277:946-949.

Holbrook, S. J., and R. J. Schmitt. 2003. Spatial and temporal variation in mortality of newly settled damselfish: patterns, causes and co-variation with settlement. Oecologia 135:532541.

Jonsen, I. D., R. S. Bourchier, and J. Roland. 2001. The influence of matrix habitat on Aphthona flea beetle immigration to leafy spurge patches. Oecologia 127:287-294.

Lecchini, D., C. W. Osenberg, J. S. Shima, C. M. St. Mary, and R. Galzin. 2007. Ontogenetic changes in habitat selection during settlement in a coral reef fish: ecological determinants and sensory mechanisms. Coral Reefs 26:423-432.

Lipcius, R. N., W. T. Stockhausen, D. B. Eggleston, L. S. Marshall, and B. Hickey. 1997. Hydrodynamic decoupling of recruitment, habitat quality and adult abundance in the Caribbean spiny lobster: source-sink dynamics? Marine and Freshwater Research 48:807-815.

McCormick, M. I. 2006. Mothers matter: crowding leads to stressed mothers and smaller offspring in marine fish. Ecology 87:1104-1109.

McCormick, M. I., and B. W. Molony. 1995. Influence of water temperature during the larval stage on size, age and body condition of a tropical reef fish at settlement. Marine Ecology Progress Series 118:59-68.

Muller, K. L., J. A. Stamps, V. V. Krishnan, and N. H. Willits. 1997. The effects of conspecific attraction and habitat quality on habitat selection in territorial birds (Troglodytes adeon). American Naturalist 150:650-661.

Murdoch, W. W. 1994. Population regulation in theory and practice. Ecology 75:271-287.

Osenberg, C. W., J. S. Shima, and C. M. St. Mary. 2006. Habitat degradation and settlement behavior: effects on fish settlement, survival, and recruitment. Pages 257-263 in Y. Suzuki, T. Nakamori, M. Hidaka, H. Kayanne, B. E. Casareto, K. Nadaoka, H. Yamano, and M. Tsuchiya, editors. Proceedings of the 10th International Coral Reef Symposium, Okinawa, Japan. Japanese Coral Reef Society, Tokyo, Japan.

Ostfeld, R. S., R. H. Manson, and C. D. Canham. 1997. Effects of rodents on survival of tree seeds and seedlings invading old fields. Ecology 78:1531-1542.

Overholtzer-McLeod, K. L. 2004. Variance in reef spatial structure masks density dependence in coral reef fish populations on natural versus artificial reefs. Marine Ecology Progress Series 276:269-280.

Palumbi, S. R. 2004. Marine reserves and ocean neighborhoods: the spatial scale of marine populations and their management. Annual Review of Environment and Resources 29:31-68.

Pettorelli, N., J. M. Gaillard, P. Duncan, J. P. Ouellet, and G. Van Laere. 2001. Population density and small-scale variation in habitat quality affect phenotypic quality in roe deer. Oecologia 128:400-405. 
Pfister, C. A., and F. R. Stevens. 2003. Individual variation and environmental stochasticity: implications for matrix model predictions. Ecology 84:496-510.

Phillips, N. E. 2005. Growth of filter-feeding benthic invertebrates from a region with variable upwelling intensity. Marine Ecology Progress Series 295:79-89.

Pulliam, H. R. 1988. Sources, sinks, and population regulation. American Naturalist 132:652-661.

Reitzel, A. M., and B. R. Chockley. 2005. Influence of habitat distribution and maternal investment on settlement of lecithotrophic larvae: modeling an ecological transition. Evolutionary Ecology Research 7:183-201.

Schmitt, R. J., and S. J. Holbrook. 2007. The scale and cause of spatial heterogeneity in strength of temporal density dependence. Ecology 88:1241-1249.

Schumaker, N. H., T. Ernst, D. White, J. Baker, and P. Haggerty. 2004. Projecting wildlife responses to alternative future landscapes in Oregon's Willamette Basin. Ecological Applications 14:381-400.

Shima, J. S. 1999. Variability in relative importance of determinants of reef fish recruitment. Ecology Letters 2: 304-310.

Shima, J. S. 2001a. Recruitment of a coral reef fish: roles of settlement, habitat, and postsettlement losses. Ecology 82: 2190-2199.

Shima, J. S. 2001b. Regulation of local populations of a coral reef fish via joint effects of density- and number-dependent mortality. Oecologia 126:58-65.

Shima, J. S. 2002. Mechanisms of density- and numberdependent population regulation of a coral-reef fish. Marine and Freshwater Research 53:175-179.

Shima, J. S., and C. W. Osenberg. 2003. Cryptic density dependence: effects of covariation between density and site quality in reef fish. Ecology 84:46-52.

Shima, J. S., C. W. Osenberg, C. M. St. Mary, and L. Rogers. 2006. Implication of changing coral communities: do larval traits or habitat features drive variation in density-dependent mortality and recruitment of juvenile reef fish? Pages 226-231 in Y. Suzuki, T. Nakamori, M. Hidaka, H. Kayanne, B. E. Casareto, K. Nadaoka, H. Yamano, and M. Tsuchiya, editors. Proceedings of the 10th International Coral Reef Symposium, Okinawa, Japan. Japanese Coral Reef Society, Tokyo, Japan.

Sih, A., G. Englund, and D. Wooster. 1998. Emergent impacts of multiple predators on prey. Trends in Ecology and Evolution 13:350-355.

Srinivasan, M. 2003. Depth distributions of coral reef fishes: the influence of microhabitat structure, settlement, and postsettlement processes. Oecologia 137:76-84.

Stachowicz, J. J., and J. E. Byrnes. 2006. Species diversity, invasion success, and ecosystem functioning: disentangling the influence of resource competition, facilitation, and extrinsic factors. Marine Ecology Progress Series 311:251262.

Stamps, J. 2006. The silver spoon effect and habitat selection by natal dispersers. Ecology Letters 9:1179-1185.

Steele, M. A., and G. E. Forrester. 2002. Variation in the relative importance of sublethal effects of predators and competitors on growth of a temperate reef fish. Marine Ecology Progress Series 237:233-245.

Van Horne, B. 1983. Density as a misleading indicator of habitat quality. Journal of Wildlife Management 47:893-901.

Vonesh, J. R., and C. W. Osenberg. 2003. Multi-predator effects across life-history stages: non-additivity of egg- and larval-stage predation in an African treefrog. Ecology Letters 6:503-508.

Wilson, J., and C. W. Osenberg. 2002. Experimental and observational patterns of density-dependent settlement and survival in the marine fish Gobiosoma. Oecologia 130:205215 . 